\title{
Correlation Between Spirometry Values and Pulmonary Artery Pressure in Young Healthy Subjects
}

\author{
Alon Grossman MD MHA, Michal Benderly PhD, Alex Prokupetz MHA, \\ Barak Gordon MD MHA, and Ofra Kalter-Leibovici MD
}

\begin{abstract}
BACKGROUND: Pulmonary hypertension is frequently associated with parenchymal lung disease. We evaluated the association between spirometry values and pulmonary artery systolic pressure (PASP) in young subjects without lung disease METHODS: We studied applicants to the Israeli Air Force, who undergo routine evaluation that includes resting spirometry and echocardiography. Applicants with overt lung disease were excluded. All echocardiographic studies performed in the years 1994 through $2010(n=6,598)$ were screened, and files that included PASP and spirometry values were analyzed for the association between PASP and FVC, FEV, $\mathrm{FEV}_{1} / \mathrm{FVC}$, peak expiratory flow, and forced expiratory flow during the middle half of the FVC maneuver. RESULTS: Of the 647 air force applicants who underwent echocardiography in which PASP was measurable and had spirometry data, $607(94 \%)$ were male, and their average age was $18.16 \pm 0.73$ years. Mean PASP was $26.4 \pm 5.2 \mathrm{~mm} \mathrm{Hg}$ (range $10-41 \mathrm{~mm} \mathrm{Hg}$ ). None of the spirometry values significantly correlated with PASP. CONCLUSIONS: PASP in young healthy subjects is not significantly associated with spirometry values. Lung mechanics probably do not contribute significantly to PASP in this population. Key words: spirometry; pulmonary hypertension; screening. [Respir Care 2014;59(3):371-374. () 2014 Daedalus Enterprises]
\end{abstract}

\section{Introduction}

Factors that contribute to pulmonary hypertension include elevated pulmonary vascular resistance, intrathoracic pressure swings due to severe airway obstruction, alveolar hypoxia, and structural changes in the pulmonary vasculature. ${ }^{1-4}$ These factors are probably more prominent in subjects with overt lung disease, but the factors determin-

Drs Grossman, Prokupetz, and Gordon are affiliated with the Israeli Air Force Aero Medical Center, Tel Hashomer, Israel. Drs Benderly and Kalter-Leibovici are affiliated with the Unit of Cardiovascular Epidemiology. The Gertner Institute for Epidemiology and Health Policy Research, affiliated with Tel Aviv University, Tel Hashomer, Israel. Dr Grossman is also affiliated with the Department of Internal Medicine E, Rabin Medical Center, Beilinson Campus affiliated to Tel Aviv University Sackler Medical School, Petah Tikva, Israel.

The authors have disclosed no conflicts of interest.

Correspondence: Alon Grossman MD, Department of Internal Medicine E, Rabin Medical Center, Beilinson Campus, 39 Jabotinski Street, Petah Tikva 49773, Israel. E-mail: alon2206@012.net.il.

DOI: $10.4187 /$ respcare.02701 ing pulmonary artery systolic pressure (PASP) in healthy subjects are less well characterized. In addition, the association between lung volumes, air flow, and PASP in young healthy subjects has not been reported. We studied the association between spirometry values and PASP, to evaluate whether healthy subjects with higher PASP have higher lung volumes and air flows than those with lower PASP.

\section{Methods}

This study was approved by the ethics committee of the Medical Corps of the Israel Defense Force.

\section{Study Population}

All applicants to the Israeli Air Force undergo preliminary evaluation at the Israel Defense Force recruitment center, and only those without important medical conditions are referred for further evaluation at the Israeli Air Force Aero Medical Center. This evaluation includes thorough history and physical examination, resting echocardiogram, and resting spirometry. Applicants with a history of asthma (active in the 5 years preceding the evaluation), 
other parenchymal lung disease, spontaneous pneumothorax are not referred for evaluation at the Israeli Air Force Aero Medical Center, and thus were excluded from the study. Applicants who were diagnosed with obstructive or restrictive lung disease during the screening process, based on basic spirometry and more extensive evaluation, if required, were disqualified from the selection process and thus excluded from the study. We included applicants evaluated at the Israeli Air Force Aero Medical Center in the years 1994 through 2010, who had measurable PASP in the presence of tricuspid regurgitation, and spirometry data in their medical files.

\section{Spirometry}

Spirometry was performed using standardized equipment and technique, as defined by the American Thoracic Society/European Respiratory Society task force. ${ }^{5}$ All applicants performed $3 \mathrm{FVC}$ maneuvers, and the best of the 3 measurements was recorded. We collected the following spirometry data: $\mathrm{FVC}, \mathrm{FEV}_{1}$, peak expiratory flow, $\mathrm{FEV}_{1} /$ $\mathrm{FVC}$, and forced expiratory flow during the middle half of the FVC maneuver. All spirometry values were corrected for height, weight, age, and sex.

\section{Echocardiography}

We reviewed all the echocardiograms of applicants performed at the Aero Medical Center between January 1994 and January 2010. All the echocardiograms were obtained with one of 3 devices: HP500 Sonos, ATL 5000HDI, or HD11 XE (all made by Philips, Eindhoven, The Netherlands). The HP500 Sonos and ATL 5000HDI were used from 1994 to 2008. The HD11 XE was used from 2008 onward. All the echocardiography studies were performed by one of 3 experienced sonographers and interpreted by one of 2 cardiologists specialized in echocardiography. Transthoracic echocardiogram included 2-dimensional Mmode and Doppler studies, per the American Society for Echocardiography guidelines for obtaining images, quantification of chamber dimensions, and assessment of valvular regurgitation. ${ }^{6-8}$ All echocardiography at the Israeli Air Force Aero Medical Center is performed in 4 windows: left and right parasternal long axis views, parasternal short axis view, and apical 4-chamber view. If elevated PASP or tricuspid regurgitation is suspected based on those 4 windows, a subcostal window is added. All tricuspid regurgitation gradients were measured during the inspiratory phase. The measurements were corrected for body surface area. The right-ventricular systolic pressure is equivalent to the PASP. The pressure gradient across the tricuspid valve was derived from tricuspid systolic regurgitant flow velocity, measured by continuous-wave Doppler, using the simplified Bernoulli equation. ${ }^{9}$ Right-atrial

\section{QUICK LOOK}

\section{Current knowledge}

Pulmonary hypertension is commonly associated with parenchymal lung disease. Factors contributing to pulmonary hypertension include increased pulmonary vascular resistance, intrathoracic pressure swings due to severe airway obstruction, hypoxia, and structural changes in the pulmonary vasculature.

\section{What this paper contributes to our knowledge}

Pulmonary artery systolic pressure in young healthy adults was not associated with spirometry values. Lung mechanics do not contribute substantially to pulmonary systolic artery pressure in young adults without lung disease.

pressure was estimated as $5 \mathrm{~mm} \mathrm{Hg},{ }^{10}$ so the rightventricular systolic pressure estimation equaled the tricuspid pressure gradient $+5 \mathrm{~mm} \mathrm{Hg}$.

We excluded any tests that indicated any cardiac abnormalities other than tricuspid regurgitation or elevated PASP, or absence of measurable regurgitant tricuspid flow.

\section{Statistical Analysis}

Demographic, spirometric, and echocardiographic data are presented as number and percent or mean $\pm \mathrm{SD}$, as applicable. The associations between tricuspid regurgitation peak and spirometry findings was assessed with Spearman correlation.

\section{Results}

A total of 6,598 subjects underwent routine echocardiography that was interpreted as normal at the Israeli Air Force Aero Medical Center during the years 1994 through 2010. Nineteen hundred studies (29\%) demonstrated tricuspid regurgitation enabling measurement of PASP. Spirometry data were available for 647 applicants (34\%). The applicants mean age was $18.16 \pm 0.73 \mathrm{y}$, and they had no important medical conditions (Table 1). Mean PASP in the entire cohort was $26.2 \pm 4.5 \mathrm{~mm} \mathrm{Hg}$, and in those for whom spirometry data were available it was $26.4 \pm 5.2 \mathrm{~mm} \mathrm{Hg}$. None of the spirometry values significantly correlated with PASP (Figs. 1 and 2). When comparing subjects whose PASP was $<17 \mathrm{~mm} \mathrm{Hg}$ to those whose PASP $>26 \mathrm{~mm} \mathrm{Hg}$, there were no significant differences in any spirometry values. 
Table 1. Demographic, Spirometric, and Echocardiographic Data

\begin{tabular}{lc}
\hline \hline Age, y & $18.16 \pm 0.73$ \\
Male, no. (\%) & $607(94)$ \\
Body surface area, ${ }^{2}$ & $2.1 \pm 0.1$ \\
Systolic blood pressure, mm Hg & $128.3 \pm 11.9$ \\
Diastolic blood pressure, mm Hg & $70.7 \pm 8.8$ \\
FVC, L & $4.58 \pm 0.7$ \\
FEV $_{1}, \mathrm{~L}$ & $4.04 \pm 0.5$ \\
FEV $_{1} / \mathrm{FVC}$ & $0.89 \pm 0.06$ \\
Peak expiratory flow, L/min $_{\text {Forced expiratory flow during the middle half }}$ & $7.96 \pm 1.5$ \\
$\quad$ of the FVC maneuver, L/min & $4.6 \pm 0.9$ \\
Pulmonary artery systolic pressure, mm Hg & \\
Aortic root, mm & $26.4 \pm 5.2$ \\
Left atrium, mm & $28.3 \pm 2.4$ \\
Posterior wall, mm & $33.6 \pm 3.7$ \\
Interventricular septum, mm & $8.8 \pm 0.8$ \\
\end{tabular}

Values are mean \pm SD unless otherwise indicated.

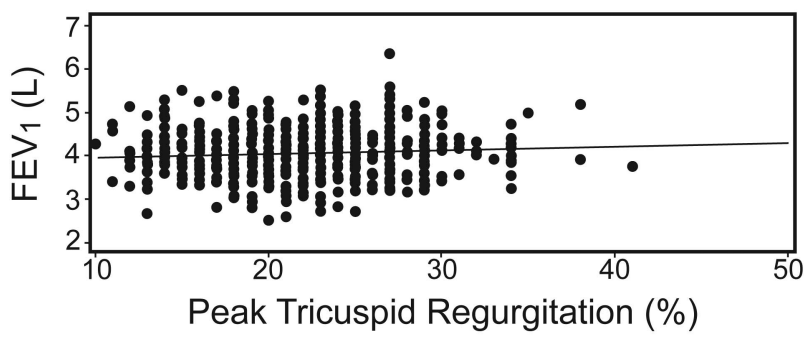

Fig. 1. Correlation between peak tricuspid regurgitation and $\mathrm{FEV}_{1}$.

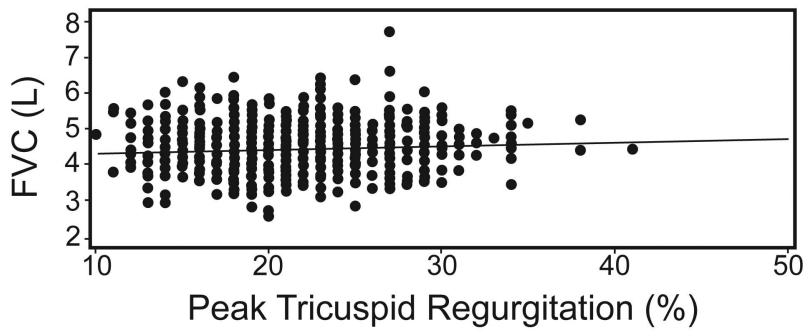

Fig. 2. Correlation between peak tricuspid regurgitation and FVC.

\section{Discussion}

The association between lung pathology and PASP is well recognized, and obstructive lung disease is one of the most common causes of pulmonary hypertension in adults. Whether PASP elevation in those patients is secondary to the lung pathology or both share a common pathogenic mechanism is unclear. Performance of spirometry and echocardiography in young, healthy subjects, in an attempt to determine the association between spirometry values within the normal range and PASP is important because it may provide preliminary evidence on the pathogenesis of pulmonary hypertension in structural lung disease. Our cohort was extremely healthy, because the screening process disqualifies all subjects with important disease. Although there are no spirometry reference values specifically for the Israeli population, the values of our cohort are similar to those reported in a large cohort from central Europe. ${ }^{12}$

PASP in young subjects correlates with left atrial diameter, left-ventricular end-diastolic and systolic diameters, and left-ventricular mass. ${ }^{13}$ These parameters all probably reflect that PASP in this population is primarily determined by increased blood volume, but it is difficult to determine the contribution of the lung to PASP in this population. We found no significant correlation between spirometry values and PASP in young, healthy subjects, so it is possible that pulmonary hypertension is a late consequence of pulmonary disease and thus not associated with normal spirometry values in asymptomatic individuals.

One of the major purposes of pre-participation screening of athletes and military recruits is to exclude obstructive lung disease, particularly because elite athletes may be at an increased risk for the development of airway injury. ${ }^{14}$ Exercise-induced asthma, a particular concern in athletes and military recruits, is a relatively common condition, which may present initially during military service or in sports. ${ }^{15}$ Military aviation may place at-risk individuals at particularly high risk for airway disease, because breathing cold dry air causes epithelial injury, and the hyperpnea performed during military aviation exposes the airway epithelium to increased shear stress and transmural pressure gradients. ${ }^{16,17}$ Yet the need for screening for exercise-induced bronchospasm is debatable, considering the relatively low yield of that screening, ${ }^{18}$ so it would seem that additional tools are required for the diagnosis of exerciseinduced bronchospasm or other forms of occult lung disease among athletes and military applicants. Because PASP in young healthy subjects is predominantly determined by increased blood flow through the pulmonary vasculature, ${ }^{13}$ lung pathology probably contributes little, if at all, to PASP.

\section{Limitations}

First, this study was retrospective, and no follow-up was performed, so the true prevalence of future lung disease is unknown. Second, only 34\% of the medical records contained both echocardiography and spirometry data, so our data set represents a relatively small percentage of the military applicants population. Third, our cohort included mostly males because flight academy is voluntary and most applicants are male. The prevalence of pulmonary hypertension is different in females and males, ${ }^{18}$ so our results are probably applicable only to males. Because many air force academy applicants are disqualified for non-medical reasons, most of our subjects could not be followed up. 
The retrospective nature of our study disallows evaluation of the development of lung pathology and whether the applicants with higher PASP on admission had a greater chance of developing overt lung disease. Because the echocardiography and spirometry were performed during the flight academy screening process, the anxiety associated with the screening process may have increased some applicants' heart rate and blood pressure and thus influenced our results. However, there is no reason to believe that those with higher PASP had a different physiologic stress response than those with lower PASP, so the association between the 2 should have remained persistent. Because we did not have reliable information on tobacco consumption in the study cohort, we could not compare smoking to non-smoking individuals. Smoking certainly affects spirometry values, ${ }^{19}$ but there is no reason to believe that smoking prevalence differed between those with different PASP values.

\section{Conclusions}

PASP in young healthy subjects was not significantly associated with spirometry values. Lung mechanics probably do not contribute significantly to PASP in this population, in which increased blood flow through the pulmonary vasculature is probably the major determinant of PASP.

\section{REFERENCES}

1. Chatila WM, Thomashow BM, Minai OA, Criner GJ, Make BJ. Co-morbidities in chronic obstructive pulmonary disease. Proc Am Thorac Soc 2008;5(4):549-555.

2. Falk JA, Kadiev S, Criner GJ, Scharf SM, Minai OA, Diaz P. Cardiac disease in chronic obstructive pulmonary disease. Proc Am Thorac Soc 2008;5(4):543-548.

3. Scharf SM, Iqbal M, Keller C, Criner G, Lee S, Fessler HE; National Emphysema Treatment Trial (NETT) Group. Hemodynamic characterization of patients with severe emphysema. Am J Respir Crit Care Med 2002;166(3):314-322.

4. Timms RM, Khaja FU, Williams GW. Hemodynamic response to oxygen therapy in chronic obstructive pulmonary disease. Ann Intern Med 1985;102(1):29-36.
5. Miller MR, Hankinson J, Brusasco V, Burgos F, Casaburi R, Coates A et al. Standardization of spirometry. Eur Respir J 2005;26(2):319338.

6. Zoghbi WA, Enriquez-Sarano M, Foster E, Grayburn PA, Kraft CD, Levine RA, et al; American Society of Echocardiography. Recommendations for evaluation of the severity of native valvular regurgitation with two-dimensional and doppler echocardiography. J Am Soc Echocardiogr 2003;16(7):777-802.

7. Lang RM, Bierig M, Devereux RB, Flachskampf FA, Foster E, Pellikka PA, et al; American Society of Echocardiography; European Association of Echocardiography. Recommendations for chamber quantification. J Am Soc Echocardiogr 2005;18(12):1440-1463.

8. Gardin JM, Adams DB, Douglas PS, Feigenbaum H, Forst DH, Fraser AG et al; American Society of Echocardiography. Recommendations for a standardized report for adult transthoracic echocardiography: a report from the American Society of Echocardiography's Nomenclature and Standards Committee and Task Force for a Standardized Echocardiography Report. J Am Soc Echocardiogr 2002;15(3):275-290.

9. Schannwell CM, Steiner S, Strauer BE. Diagnostics in pulmonary hypertension. J Physiol Pharmacol 2007;58(Suppl 5 Pt 2):591-602.

10. McQuillan BM, Picard MH, Leavitt M, Weyman AE. Clinical correlates and reference intervals for pulmonary artery systolic pressure among echocardiographically normal subjects. Circulation 2001; 104(23):2797-2802.

11. Rochat MK, Laubender RP., Kuster D, Braendli O, Moeller A, Mansmann U et al, Spirometry reference equations for central European populations from school age to old age. PLoS ONE 8(1):e52619.

12. Grossman A, Prokupetz A, Benderly M, Wand O, Assa A, KalterLeibovici O. Pulmonary artery pressure in young healthy subjects. J Am Soc Echocardiogr 2012;25(3):357-360.

13. Kippelen P, Fitch KD, Anderson SD, Bougault V, Boulet LP, Rundell KW et al. Respiratory health of elite athletes- preventing airway injury: a critical review. Br J Sports Med 2012;46(7):471-476.

14. Carlsen KH, Hem E, Stensrud T. Asthma in adolescent athletes. Br J Sports Med 2011;45(16):1266-1271.

15. Kippelen $\mathrm{P}$, Anderson SD. Airway injury during high-level exercise. Br J Sports Med 2012;46(6):385-90.

16. Anderson SD, Holzer K. Exercise-induced asthma: is it the right diagnosis in elite athletes? J Allergy Clin Immunol 2000;106(3):419428.

17. Parsons JP, Cosmar D, Phillips G, Kaeding C, Best TM, Mastronarde JG. Screening for exercise: induced bronchoconstriction in college athletes. J Asthma 2012;49(2):153-157.

18. Robles AM, Shure D. Gender issues in pulmonary vascular disease. Clin Chest Med 2004;25(2):373-377.

19. Thompson JE, Sleigh AC, Passey ME, Barnes A, Streatfield RW. Ventilatory standards for clinically well aboriginal adults. Med J Aust 1992;156(8):566-569. 